\title{
Association between chronic diseases and falls among a sample of older people in Finland
}

\author{
Milla Immonen ${ }^{1,2^{*}} \mathbb{D}$, Marianne Haapea ${ }^{2,3,4}$, Heidi Similä ${ }^{1}$, Heidi Enwald ${ }^{4,5}$, Niina Keränen ${ }^{6}$, Maarit Kangas ${ }^{6}$,
} Timo Jämsä ${ }^{3,4,6}$ and Raija Korpelainen ${ }^{2,4,7}$

\begin{abstract}
Background: Falls are a major problem for older people and recurrent fallers are especially prone to severe consequences due to falls. This study investigated the association between chronic conditions and falls.

Methods: Responses from 872 older persons (age 65-98) to a health questionnaire were used in the analyses. Characteristics and disease prevalence between recurrent fallers, one-time fallers and non-fallers were compared. A hierarchical clustering method was applied to find combinations of chronic conditions that were associated with recent recurrent falling.

Results: The results showed that recurrent fallers had a higher number of diseases (median 4, interquartile range, $\mathrm{IQR}=2.0-5.0$ ) compared to non-fallers (median 2, IQR =1.0-3.0). Eight clusters were formed based on the data. The participants in the low chronic disease cluster were younger, more physically active, not frail, and had fewer geriatric conditions. Multiple chronic disease cluster participants were older, less physically active, overweight (body mass index, BMI > 30), at risk of malnutrition, and had more geriatric conditions. Significantly increased risk of recurrent falls relative to the low chronic cluster was found for respondents in the osteoporosis cluster and multiple chronic disease cluster $(\mathrm{OR}=5.65,95 \%$ confidence interval $\mathrm{Cl}: 1.23-25.85, p=0.026$, and $\mathrm{OR}=13.42,95 \% \mathrm{Cl}: 2.47-$ $72.96, p=0.002$, respectively). None of the clusters were associated with increased risk of one-time falling.

Conclusions: The results implicate that the number of chronic diseases is related with risk of recurrent falling. Furthermore, the results implicate the potential of identifying certain combinations of chronic diseases that increase fall risk by analyzing health record data, although further studies are needed with a larger population sample.
\end{abstract}

Keywords: Falls, Recurrent falls, Fall risk, Chronic diseases, Older adults, Geriatrics, Gerontology, Aging

\section{Background}

Falls of older adults are globally a major health, economic and societal problem. One third of people over 65 years old fall at least once every year [1-5] and the number of falls per year increases with age and frailty

\footnotetext{
* Correspondence: milla.immonen@vtt.fi

${ }^{1}$ VTT Technical Research Centre of Finland Ltd. Kaitoväylä 1, P.O.Box 1100, Fl-90571 Oulu, Finland

${ }^{2}$ Center for Life Course Health Research, University of Oulu, P.O. Box 5000, Fl-90014 Oulu, Finland

Full list of author information is available at the end of the article
}

level [6, 7]. Falls are associated with increased mortality, morbidity, reduced functioning, impaired quality of life and premature nursing home admissions [8]. Fear of falling may increase even after a non-injurious fall [9]. It can lead to a negative cycle where the activity of the person reduces, followed by a reduction in functionality. That, in turn, increases the need for help in daily activities $[10,11]$. The world's population is ageing rapidly; the number of people aged 65 or older is expected to grow from 524 million in 2010 to nearly 1.5 billion in

(c) The Author(s). 2020 Open Access This article is licensed under a Creative Commons Attribution 4.0 International License, which permits use, sharing, adaptation, distribution and reproduction in any medium or format, as long as you give appropriate credit to the original author(s) and the source, provide a link to the Creative Commons licence, and indicate if changes were made. The images or other third party material in this article are included in the article's Creative Commons licence, unless indicated otherwise in a credit line to the material. If material is not included in the article's Creative Commons licence and your intended use is not permitted by statutory regulation or exceeds the permitted use, you will need to obtain permission directly from the copyright holder. To view a copy of this licence, visit http://creativecommons.org/licenses/by/4.0/ The Creative Commons Public Domain Dedication waiver (http://creativecommons.org/publicdomain/zero/1.0/) applies to the data made available in this article, unless otherwise stated in a credit line to the data. 
2050 [12]. Rapidly increasing ageing populations are a challenge to limited social and health care systems. At the same time, the costs resulting from falls and their consequences are increasing rapidly, and the importance of fall prevention grows. Screening for high fall risk persons consumes resources and public funding. Efficient methods for screening fall risk are needed to find the persons at most risk to target preventive actions towards them. Identifying recurrent fallers is especially important as they are more prone to severe consequences compared to non-recurrent fallers. For example, in a prospective study by Pluijm et al. $11.9 \%$ of recurrent fallers (at least two falls within 6 months) had a fall-related fracture compared to $3.4 \%$ of non-recurrent fallers [13]. One-time fallers ( 1 fall within 1 year) and recurrent fallers are reported to have distinct characteristics with respect to age, physiology, cognition, fear of falling and ability to perform daily activities [14-16].

Several chronic conditions have been identified to be associated with the higher prevalence of falling, including Parkinson's disease [17, 18], heart failure [19], cognitive impairments [1, 20], diabetes [21], arthritis [22], depression [7, 23] and chronic kidney disease [24, 25]. In addition, conditions such as osteoporosis further increase the risk of fractures [26]. Along with the age, the prevalence of multiple chronic conditions increases [27-29], and earlier studies have identified co-occurrence of diseases and multi-morbidity patterns among older adults [30-32]. An association between history of falls and the number of diseases and the number of health conditions have been found, and the amount of falls rises with the number of diseases [32, 33]. Only a few studies have assessed, if there is a relationship between falls and multiple chronic conditions or multi-morbidity patterns [32, $34,35]$. Related to multi-morbidity studies, an agreement on which diseases should be included in the multimorbidity assessment is missing. Based on a systematic literature review, Diederichs et al. recommended to include a minimum of 11 diseases (cancer, diabetes mellitus, depression, hypertension, myocardial infarction, chronic ischaemic heart disease, heart arrhythmias, heart insufficiency, stroke, chronic obstructive pulmonary disease, and arthritis) that are highly prevalent in the older population in the multi-morbidity assessment [36]. Moreover, Fortin et al. recommended that investigators designing future studies to assess the prevalence of multi-morbidity should consider the number of diagnoses to be assessed (with 12 or more frequent diagnoses of chronic diseases appearing ideal) and should attempt to report results for differing definitions of multi-morbidity (both 3 or more diseases and the classic 2 or more diseases) [37]. Recently, Griffith et al. concluded that the suitability of existing multimorbidity measures for use in a specific research study depends on study-related factors such as purpose of the study, outcomes examined and preferences of the involved stakeholders [38]. In an extensive study using selfreported falls and disease data from 16,357 community dwelling older adults, Sibley et al. found falls to associate with a number of chronic conditions and with chronic disease patterns [32]. Another recent study with 149,876 respondents resulted in two "at risk" populations characterized by different chronic disease combinations and age. The authors concluded that these groups might benefit from different risk stratification and interventions [35]. In a sample of 2566 Swedish older adults, unhealthy lifestyle and high burden of chronic diseases were found to increase the risk of falling over long follow-up periods (5 and 10 years) [34]. Identifying diseases and possible individual clusters of certain conditions associated with risk of falling would help to develop solutions for screening those most at risk among older populations. Utilizing existing data saved on electronic health record provides a possibility for easy and cost-effective screening for high fall risk persons. Even though specific diseases have been identified to increase the risk of falling, and the number of chronic conditions have been linked to higher risk of falling, current fall prevention guidelines do not instruct measuring the amount of chronic conditions. The amount of earlier studies linking the amount or individual clusters of chronic conditions with higher fall risk is still very small [32, 34, 35]. Verifying the results with another sample help in improving fall prevention guidelines by recommending comprehensive fall assessment, or interventions aiming for fall prevention, among older adults with combinations of certain conditions that are connected with higher risk of falling. Thus, the aim of this study was to reveal the prevalence of falls and the association between number of chronic conditions and occurrence of recent falls, and the association between individual or multiple chronic conditions and occurrence of recent falls in a population-based sample of older people. In addition, demographic differences and lifestyle characteristics between non-fallers, one-time fallers and recurrent fallers were studied.

\section{Methods}

A survey was conducted between November 2014 and January 2015 in Oulu, Finland. Oulu has a population of approximately 200,000 and it is Finland's fifth largest city, located in Northern Finland. Of the population, $14 \%$ was aged 65 years or more at the end of 2014 [39]. The survey was part of a research study: Tailored Services for Elderly - Gamified remote service concept for promoting health of older people (GASEL-project, 2014-2016). Eleven volunteer seniors piloted the study questionnaire, and their feedback was used to make minor usability-related changes. A random sample of 1500 people living in Oulu was obtained from the Population Register Centre of Finland. The sampling criteria 
were: 1) born during 1.1.1900-31.12.1949 (aged 65-114 by the end of 2014);2) spoke Finnish as a native language; and 3) had a permanent living address in Oulu in November 2014. A reminder and another copy of the questionnaire were sent to the non-responders 4 weeks after the first survey. The sample of 1500 persons represents approximately $5.5 \%$ of the over 65 -year-old persons living in the city of Oulu and 918 persons (61.2\%) responded to the survey (3.3\% of the over 65-year-olds).

The study protocol was approved by the Ethics Committee of Human Sciences at the University of Oulu (statement 6/2014). The extensive questionnaire included items related to the participants' socio-demographic background, perceived loneliness, stress, health, medication, social participation, personality, physical activity, functional ability, occurrence of recent falls, fear of falling, Internet and communications technology (ICT) use, and gaming. The questionnaire is available as supplementary material (Supplementary file 1, GASEL questionnaire (English version)).

To determine if the respondent had diseases diagnosed by a medical professional the question: "Do you currently have any of the following conditions as diagnosed by a medical professional?" and the answer options "yes" or "no" were used. The complete list of asked diseases can be found from the Supplementary file 1.

Frequency of recent falls was determined by the question: "Have you fallen during the last three (3) months? (A fall is defined as an event that results in a person coming to rest inadvertently on the ground or floor or other lower level)." The answer options were: "no" or "yes, ___ times." Three month recall time was chosen, because in the target group the possibility of poorer cognitive function may lead to potential bias with longer recall time [40, 41].

The respondents were categorized according to their self-reported alcohol use into three categories: no alcohol, light drinker (1-3 drinks per week), moderate (4-7 drinks per week for women and 4-14 drinks per week for men), and heavy ( $\geq 8$ drinks per week for women and $\geq 15$ drinks per week for men) [42]. Smoking was categorized according to their selection of options: 1) I don't smoke at all, 2) I quit smoking in year 3) I currently smoke cigarettes a day, 4) I use snuff or other tobacco products other than cigarettes. Activity level was determined by the question: "How long are you active each day? (e.g. biking/walking, housework, walking to the store, exercise hobbies, etc.)? 1) < 1 hour per day, 2) 1-2 hours per day, and 3) > 2 hours per day" [43]. Sleep quality was determined by the question: "How do you feel about the quality of sleep you are currently getting (regardless of how much you sleep)?" and the answer options: 1) good 2) satisfactory, or 3) poor. "Can you rise from a chair independently without using your hands?" was used as a question to determine if the person was able to stand up from a chair. The answer options were: 1) I am able to rise independently without using my hands, 2) I am able to rise independently using my hands on first try, 3) I am able to rise using my hands after several tries, 4) I need minimal assistance to rise, and 5) I need moderate or maximal assistance to rise." A modified SOF Frailty Index (Study of Osteoporotic Fractures) [44] described in our earlier study [45] was used to identify those with frailty symptoms. The modified items were: 1 . Weight loss irrespective of intention to lose weight (if weight loss in 3 months is equal or more than $1 \mathrm{~kg}$, score $=1$ ), 2. "Can you rise from a chair independently without using your hands?" (if unable to rise from a chair, score $=1$ ), and 3. Poor energy as identified by "Which of the following best describes how energetic you have felt in the last month?" (with the response "I feel moderately/very/extremely exhausted, tired or powerless", score $=1$ ). The subject's status was categorized as frail if the SOF index was 2 or 3 ; intermediate if the SOF index was 1 , and robust if the SOF index was 0. The Mini Nutritional Assessment (MNA) [46] includes seven questions about decrease in nutrition, weight loss, mobility, stress or acute illness, neuropsychological problems (dementia or depression), and Body Mass Index (BMI). Compared to the original MNA questionnaire, in our study weight loss was determined by the question: "In the last 3 months, has your weight 1) decreased by __ $\mathrm{kg}$ (if the decrease is more than $3 \mathrm{~kg}$, score $=0$, if the decrease is between $1 \mathrm{~kg}$ and $3 \mathrm{~kg}$, score $=2), 2$ ) stayed the same (score $=3), 3$ ) increased by _ $\mathrm{kg}$ (score $=3$ ), and 4) I don't know (score $=1)$." Moreover, the question about psychological problems was modified: "Do you currently have any of the following conditions as diagnosed by a medical professional?" was used as a question to discover if the respondent had memory disorders (mild or moderate to severe), other neurological illness, or depression, with the answer options "yes" or "no." In our modified MNA, 0 points is given if the respondent had moderate or severe memory disorder and/or depression, 1 point is given for mild memory disorder and 2 points is given if the respondent didn't have memory disorders or depression. An individual is considered to have malnutrition if their total MNA score is $0-7$ points, to be at risk of malnutrition at $8-11$ points, and to have normal nutrition at $12-14$ points.

\section{Statistical analysis}

Analyses were performed using IBM SPSS Statistics for Windows, version 24 (IBM Corp., Armonk, NY, USA). The individual was classified as a non-faller, if he or she did not report any falls during the period of last 3 months. If the individual had fallen once during the last 
3 months, he or she was categorized as a one-time faller and if the individual had fallen at least twice during the last 3 months he or she was categorized as recurrent faller. To describe the characteristics of the participants, frequencies with proportions and means with standard deviations were calculated separately for non-fallers, one-time-fallers and recurrent fallers. Chi-square test, analysis of variance (ANOVA) and Kruskal-Wallis test were used to analyze the statistical significance of the differences between non-fallers, one-time fallers and recurrent fallers in dichotomic, continuous, and nonnormally distributed continuous variables, respectively. The background and lifestyle related variables were used to present the sample characteristics but they were not used in the cluster analysis.

If a respondent answered "yes" or "no" to at least one of the diseases but left the rest of the disease questions unanswered, the answers to the blank questions were interpreted as "no." If the respondent didn't choose any of the diseases, the respondent's disease data were interpreted as missing. The number of chronic diseases was calculated. Chi-square test and Kruskal-Wallis test were used to compare the dichotomic disease variables and not normally distributed number of diseases -variable, respectively, between recurrent fallers, one-time fallers and non-fallers. Multinomial logistic regression was performed to analyze the relationship between the number of chronic diseases and falls.

To determine if there was an association between different combinations of chronic conditions and recent falling, a two-step statistical procedure was applied. To identify sub-groups of individuals according to their responses about currently having a chronic disease diagnosed by a doctor, a method of agglomerative hierarchical clustering with Ward's linkage was used [47]. Following 15 diseases were included in clustering: diabetes, rheumatoid arthritis, coronary heart disease, elevated blood pressure, blood circulation problems in the brain, blood circulation problems in the legs, hypothyroidism, cancer, asthma, chronic obstructive

Table 1 Study population characteristics

\begin{tabular}{|c|c|c|c|c|c|c|}
\hline \multicolumn{2}{|l|}{ Variable } & \multirow{2}{*}{$\begin{array}{l}\text { Non-faller }(n=756) \\
72.7(6.5)\end{array}$} & \multirow{2}{*}{$\begin{array}{l}\text { One-time faller }(n=71) \\
76.6(6.9)\end{array}$} & \multirow{2}{*}{$\begin{array}{l}\text { Recurrent faller }(n=45) \\
76.0(8.2)\end{array}$} & \multirow{2}{*}{$\frac{\text { All }(n=872)}{73.2(6.7)}$} & \multirow{2}{*}{$\frac{p \text {-value }}{<0.001}$} \\
\hline$\overline{\mathrm{Age}^{a}}$ & & & & & & \\
\hline \multirow[t]{2}{*}{ Gender } & Male & 319 (42.2\%) & $30(42.3 \%)$ & $20(44.4 \%)$ & $359(43.4 \%)$ & \multirow[t]{2}{*}{0.957} \\
\hline & Female & $437(57.8 \%)$ & $41(57.7 \%)$ & $25(55.6 \%)$ & $503(57.7 \%)$ & \\
\hline $\mathrm{BMI}$ & & $26.7(4.7)$ & $27.3(4.0)$ & $27.1(6.0)$ & $26.8(4.7)$ & 0.584 \\
\hline \multirow[t]{4}{*}{$\mathrm{BMI}$} & $<20$ & $16(2.2 \%)$ & $2(3.0 \%)$ & $4(9.1 \%)$ & $22(2.6 \%)$ & \multirow[t]{4}{*}{0.067} \\
\hline & $20-24.9$ & $267(36 \%)$ & $17(25.4 \%)$ & $13(29.5 \%)$ & $297(34.8 \%)$ & \\
\hline & $25-29.9$ & $323(43.5 \%)$ & $34(50.7 \%)$ & $17(38.6 \%)$ & $374(43.8 \%)$ & \\
\hline & $>30$ & $136(18.3 \%)$ & $14(20.9 \%)$ & $10(22.7 \%)$ & $160(18.8 \%)$ & \\
\hline \multirow[t]{4}{*}{ Alcohol use } & No alcohol & $337(46.6 \%)$ & $42(63.6 \%)$ & $21(48.8 \%)$ & $400(48 \%)$ & \multirow[t]{4}{*}{0.153} \\
\hline & Light & $255(35.3 \%)$ & $17(25.8 \%)$ & $12(28 \%)$ & $284(34 \%)$ & \\
\hline & Moderate & $104(14.4 \%)$ & $6(9.1 \%)$ & $9(21 \%)$ & $119(14 \%)$ & \\
\hline & Heavy & $27(3.7 \%)$ & $1(1.5 \%)$ & $1(2 \%)$ & $29(3 \%)$ & \\
\hline \multirow[t]{3}{*}{ Physical activity, daily hours } & $<1 \mathrm{~h}$ & $113(15.2 \%)$ & $14(19.7 \%)$ & $12(27.9 \%)$ & $139(16 \%)$ & \multirow[t]{3}{*}{0.076} \\
\hline & $1-2 h$ & $247(33.2 \%)$ & $25(35.2 \%)$ & $17(39.5 \%)$ & $289(34 \%)$ & \\
\hline & $>2 \mathrm{~h}$ & $383(51.5 \%)$ & $32(45.1 \%)$ & $14(32.6 \%)$ & $429(50 \%)$ & \\
\hline \multicolumn{2}{|c|}{ Current smoker (> 1 cigarettes per day) } & $63(8.5 \%)$ & $1(1.4 \%)$ & $5(12 \%)$ & $69(8 \%)$ & 0.079 \\
\hline \multicolumn{2}{|l|}{ Sleep quality: Poor } & $52(7.1 \%)$ & $8(12.5 \%)$ & $8(19.5 \%)$ & $68(8 \%)$ & 0.036 \\
\hline \multicolumn{2}{|c|}{ Ability to rise from a chair without using hands } & $636(86.2 \%)$ & $54(79.4 \%)$ & $17(39.5 \%)$ & $707(80 \%)$ & $<0.001$ \\
\hline \multirow[t]{3}{*}{ SOF-index (frailty) } & Robust & $509(71.0 \%)$ & $38(57.6 \%)$ & $14(35 \%)$ & $561(68 \%)$ & \multirow[t]{3}{*}{$<0.001$} \\
\hline & Intermediate & $167(23.3 \%)$ & $23(34.8 \%)$ & $10(25 \%)$ & $200(24 \%)$ & \\
\hline & Frail & $41(5.7 \%)$ & $5(7.6 \%)$ & $16(40 \%)$ & $62(8 \%)$ & \\
\hline \multirow[t]{3}{*}{ MNA } & Malnutrition & $6(1.3 \%)$ & $0(0.0 \%)$ & $0(0 \%)$ & $6(1 \%)$ & \multirow[t]{3}{*}{0.005} \\
\hline & Risk of malnutrition & $58(12.3 \%)$ & $9(22.5 \%)$ & $9(37.5 \%)$ & $76(14 \%)$ & \\
\hline & Normal nutrition & 406 (86.4\%) & 31 (77.5\%) & $15(62.5 \%)$ & $452(85 \%)$ & \\
\hline
\end{tabular}

Values are numbers (percentage of number of participants having data on the variable in question) or means (standard deviation) BMI Body mass index, SOF SOF Frailty Index (Study of Osteoporotic Fractures), MNA Mini Nutritional Assessment

${ }^{a}$ Median age (interquartile range, IQR): non-fallers 71 years (68-77), one-time fallers 78 (71-82), recurrent fallers 73 years (68-83) 
pulmonary disease (COPD), heart failure, osteoporosis, mild, moderate or severe cognitive impairment, depression. Due to low prevalence, hyperthyroidism, Parkinson's disease, liver diseases, eating disorder, kidney diseases, and mental illnesses (other than depression) were excluded in the cluster analysis, and due to vague definition and variety of diseases, the "other diseases" group was not included. Hierarchical clustering begins by treating each subject as an individual cluster. These clusters are gradually merged with the most similar other clusters until all subjects are included in a single cluster. This method produces a tree-like structure, a dendogram. The number of result clusters was chosen by visually inspecting the dendogram and agglomeration schedule coefficient and by analyzing the multiple morbidities inside the clusters. The cluster solution was validated by selecting a $50 \%$ random sample of the data and running the same agglomerative hierarchical clustering procedure in this sub-sample. The cluster memberships from the sub-sample were compared with the original memberships. Eventually, the relationship between chronic disease clusters and one-time and recurrent falls was studied by multinomial logistic regression, adjusted for age and gender. Similar methodology has been used in previous studies by Sibley et al. [32] and Ek et al. [34].

\section{Results}

Eligible data on 872 participants were available. Of the respondents, $116(13.3 \%)$ had fallen during the last 3 months. Seventy-one (8.4\%) had fallen once, 27 (3.1\%) two times, $10(1.1 \%)$ three times, $3(0.3 \%)$ four times and 5 (0.6\%) more than five times. The characteristics of the study participants are presented in Table 1 . Non-fallers were younger than the one-time or recurrent fallers (mean age 72.7, 76.6 and 76.0 years, respectively, $p<0.001$ ). Categorization as frail was more common among recurrent fallers than non-fallers or one-time fallers (40.0, 5.7

Table 2 Prevalence of diagnosed diseases among fallers and non-fallers

\begin{tabular}{|c|c|c|c|c|c|}
\hline & $\begin{array}{l}\text { All } \\
n=872\end{array}$ & $\begin{array}{l}\text { Non-fallers } \\
n=756\end{array}$ & $\begin{array}{l}\text { One-time fallers } \\
n=71\end{array}$ & $\begin{array}{l}\text { Recurrent fallers } \\
n=45\end{array}$ & $P$-value \\
\hline Number of diseases* & $2.0(2.0-3.0)$ & $2(1.0-3.0)$ & $3(1-3.3)$ & $4(2.0-5.0)$ & $<0.001^{*}$ \\
\hline At least one of the stated diseases & $712(83.6 \%)$ & $611(80.8 \%)$ & $61(85.9 \%)$ & $40(88.8 \%)$ & 0.681 \\
\hline Diabetes & $218(25.6 \%)$ & $180(23.8 \%)$ & $21(23.9 \%)$ & $17(37.8 \%)$ & 0.058 \\
\hline Rheumatoid arthritis & $37(4.3 \%)$ & $27(3.6 \%)$ & $5(7.0 \%)$ & $5(11.1 \%)$ & 0.022 \\
\hline Coronary heart disease & $161(18.9 \%)$ & $131(17.3 \%)$ & $17(23.9 \%)$ & $13(28.9 \%)$ & 0.062 \\
\hline Elevated blood pressure & $417(49.2 \%)$ & $362(47.9 \%)$ & $32(45.1 \%)$ & $23(51.1 \%)$ & 0.72 \\
\hline Blood circulation problems in the brain & $57(6.7 \%)$ & $43(5.7 \%)$ & $4(5.6 \%)$ & $10(22.2 \%)$ & $<0.001$ \\
\hline Blood circulation problems in the legs & $138(16.2 \%)$ & $109(14.4 \%)$ & $14(19.7 \%)$ & $15(33.3 \%)$ & 0.002 \\
\hline hypothyroidism & $109(12.8 \%)$ & $93(12.3 \%)$ & $10(14.1 \%)$ & $6(13.3 \%)$ & 0.898 \\
\hline Cancer & $71(8.4 \%)$ & $58(7.7 \%)$ & $8(11.3 \%)$ & $5(11.1 \%)$ & 0.432 \\
\hline Asthma & $102(12.0 \%)$ & $86(11.4 \%)$ & $8(11.3 \%)$ & $8(17.8 \%)$ & 0.388 \\
\hline COPD & $32(3.8 \%)$ & $28(3.7 \%)$ & $3(4.2 \%)$ & $1(2.2 \%)$ & 0.861 \\
\hline Cardiac failure & $81(9.5 \%)$ & $62(8.2 \%)$ & $8(11.3 \%)$ & $11(24.4 \%)$ & 0.001 \\
\hline Osteoporosis & $62(7.3 \%)$ & $46(6.1 \%)$ & $8(11.3 \%)$ & $8(17.8 \%)$ & 0.004 \\
\hline Parkinson's disease & $11(1.3 \%)$ & $5(0.7 \%)$ & $2(2.8 \%)$ & $4(8.9 \%)$ & $<0.001$ \\
\hline Moderate or severe cognitive impairment & $23(2.7 \%)$ & $14(1.9 \%)$ & $3(4.2 \%)$ & $6(13.3 \%)$ & $<0.001$ \\
\hline Mild cognitive impairment & $106(12.5 \%)$ & $78(10.3 \%)$ & $16(22.5 \%)$ & $12(26.7 \%)$ & $<0.001$ \\
\hline Depression & $41(4.8 \%)$ & $24(3.2 \%)$ & 7 (9.9\%) & $10(26.7 \%)$ & $<0.001$ \\
\hline Other disease & $108(12.7 \%)$ & 90 (11.9\%) & $9(12.7 \%)$ & $9(20.0 \%)$ & 0.245 \\
\hline Liver disease & $5(0.6 \%)$ & $5(0.7 \%)$ & $0(0 \%)$ & $0(0 \%)$ & 0.681 \\
\hline Kidney disease & $15(1.8 \%)$ & $11(1.5 \%)$ & $1(1.4 \%)$ & $3(7 \%)$ & 0.028 \\
\hline Eating disorder & $4(0.5 \%)$ & $3(0.4 \%)$ & $0(0.0 \%)$ & $1(2.3 \%)$ & 0.168 \\
\hline Other mental disorder & $7(0.8 \%)$ & $6(0.8 \%)$ & $1(1.4 \%)$ & $0(0.0 \%)$ & 0.714 \\
\hline Urinary incontinence & $215(25.2 \%)$ & $166(22.0 \%)$ & $25(35.2 \%)$ & $24(55.8 \%)$ & $<0.001$ \\
\hline Dizziness & $226(26.7 \%)$ & $176(24.0 \%)$ & $25(35.2 \%)$ & $25(56.8 \%)$ & $<0.001$ \\
\hline
\end{tabular}

Values are numbers (\%), or medians (interquartile range, IQR), COPD chronic obstructive pulmonary disease

* Kruskal-Wallis. Mean number of diseases (standard deviation): non-fallers 2.17 (1.95), one-time fallers 2.74 (2.18), recurrent fallers 4.14 (2.52) 
and 7.6\%, respectively, $p<0.001)$ and fallers were less frequently able to get up from a chair without using hands or without assistance than non-fallers or one-time fallers (39.7, 86.2, 79.4\%, $p<0.001$ ). Fallers had symptoms of malnutrition more often than non-fallers $(37.5 \%$ for recurrent fallers, $22.5 \%$ for one-time fallers and $12.3 \%$ for nonfallers, $p=0.005)$. Recurrent fallers also had poor selfreported sleep quality more often than non-fallers or onetime fallers (19.5, 7.1 and $12.5 \%$, respectively, $p=0.036$ ).

The occurrence of chronic diseases and common geriatric conditions, urinary incontinence and dizziness, in the groups of fallers and non-fallers are shown in Table 2 . The median number of diseases differed significantly in the groups of non-fallers, one-time fallers and recurrent fallers (medians 2, 3 and 4 , respectively; $p<0.001$ ). The frequency of rheumatoid arthritis, blood circulation problems in the brain and legs, cardiac failure, osteoporosis, Parkinson's disease, moderate or severe cognitive impairment, mild cognitive impairment, depression, urinary incontinence, and dizziness were higher among recurrent fallers than non-fallers or one-time fallers (Table 2).

The number of chronic diseases and their relationship to recurrent falls are shown in Table 3. According to age and gender -adjusted multinomial logistic regression, the respondents with five or more chronic diseases significantly more often reported having two or more falls during the last 3 months than the participants with less chronic diseases. The odds ratio for having experienced recurrent falls was 11.70 (95\% CI: 2.99-46.44) with five chronic diseases and 8.60 (95\% CI: 2.10-35.17) with six or more chronic diseases compared to no chronic diseases.

Agglomerative hierarchical clustering with Ward's linkage resulted in eight clusters. The formed clusters are shown in Table 4. Cluster 1 participants had a low number of chronic conditions. Cluster 2 participants had the highest prevalence of elevated blood pressure. Cluster 3 participants had coronary artery disease, and heart failure as well as diabetes. Cluster 4 participants had asthma and COPD, and Cluster 5 participants hypothyroidism and diabetes. Cluster 6 in the main included participants with osteoporosis, but the prevalence of elevated blood pressure was not seemingly high compared to the other clusters. Cluster 7 consisted of participants with blood circulation problems in the legs. The multiple chronic disease Cluster 8 included 32 participants who had a higher prevalence of multiple chronic conditions; elevated blood pressure, diabetes, coronary heart disease, heart failure, cognitive impairments, blood circulation problems in brain and legs, asthma, COPD and rheumatoid arthritis. The formed clusters were labeled after the disease, which prevalence in the cluster exceeds the prevalence in the total sample and the prevalence in the other clusters, except for the elevated
Table 3 Association between number of chronic diseases and falls according to multivariable logistic regression analysis adjusted for age

\begin{tabular}{|c|c|c|c|}
\hline & Variable & OR $(95 \% \mathrm{Cl})$ & $P$-value \\
\hline \multirow[t]{11}{*}{ One-time faller } & No chronic diseases & reference & \\
\hline & One chronic disease & 0.392 & 0.392 \\
\hline & Two chronic diseases & 0.526 & 0.526 \\
\hline & Three chronic diseases & 0.424 & 0.424 \\
\hline & Four chronic diseases & 0.770 & 0.770 \\
\hline & Five chronic diseases & 0.616 & 0.616 \\
\hline & Six or more chronic diseases & 0.529 & 0.529 \\
\hline & Age 65-74 & reference & \\
\hline & Age $75-84$ & $4.48(2.56-7.83)$ & $<0.001$ \\
\hline & Age $\geq 85$ & $2.78(1.03-7.48)$ & 0.044 \\
\hline & Gender & $0.98(0.59-1.65)$ & 0.951 \\
\hline \multirow[t]{11}{*}{ Recurrent faller } & No chronic diseases & reference & \\
\hline & One chronic disease & $0.72(0.14-3.64)$ & 0.692 \\
\hline & Two chronic diseases & $1.30(0.30-5.60)$ & 0.723 \\
\hline & Three chronic diseases & $2.92(0.76-11.19)$ & 0.116 \\
\hline & Four chronic diseases & $1.82(0.35-9.47)$ & 0.474 \\
\hline & Five chronic diseases & $11.7(2.99-46.44)$ & 0.000 \\
\hline & Six or more chronic diseases & $8.60(2.10-35.17)$ & 0.003 \\
\hline & Age 65-74 & reference & \\
\hline & Age $75-84$ & $1.00(0.47-2.13)$ & 0.947 \\
\hline & Age $\geq 85$ & $2.07(0.82-1.07)$ & 0.122 \\
\hline & Gender (female) & $1.05(0.54-1.05)$ & 0.870 \\
\hline
\end{tabular}

OR Odds ratio, $\mathrm{Cl}$ Confidence Interval

blood pressure. In the split sample for validation, agglomerative hierarchical clustering formed similarly eight clusters, of which one cluster included healthy participants and one cluster included participants with multiple chronic conditions.

The identified clusters also differed with regard to demographic characteristics and geriatric conditions, as shown in Table 5. The participants in Cluster 1 were younger, more physically active, more frequently non-frail, and had smaller prevalence of geriatric conditions such as urinary incontinence and dizziness. In contrast, multi-morbid Cluster 8 participants were older, less physically active, more often overweight (BMI > 30), at risk of malnutrition, and had higher prevalence of geriatric conditions such incontincence and dizziness.

Multinomial logistic regression analyses (Table 6) showed that Cluster 6 (osteoporosis, OR $=5.65,95 \% \mathrm{CI}$ : 1.23-25.85, $p=0.026$ ) and Cluster 8 (multiple chronic disease, $\mathrm{OR}=13.42,95 \% \mathrm{CI}: 2.47-72.96, \mathrm{p}=0.002)$ were significantly associated with recurrent falling ( $\geq 2$ falls during the last 3 months) relative to Cluster 1 (low- 
Table 4 Chronic diseases by cluster

\begin{tabular}{|c|c|c|c|c|c|c|c|c|c|}
\hline Cluster & 1 & 2 & 3 & 4 & 5 & 6 & 7 & 8 & Total \\
\hline Label & $\begin{array}{l}\text { Low } \\
\text { chronic } \\
\text { disease }\end{array}$ & $\begin{array}{l}\text { Elevated } \\
\text { blood } \\
\text { pressure }\end{array}$ & $\begin{array}{l}\text { Coronary } \\
\text { artery } \\
\text { disease }\end{array}$ & Asthma & Hypothyroidism & Osteoporosis & $\begin{array}{l}\text { Blood circulation } \\
\text { problems in legs }\end{array}$ & $\begin{array}{l}\text { Multiple } \\
\text { chronic } \\
\text { disease }\end{array}$ & \\
\hline N & 138 & 227 & 100 & 64 & 59 & 176 & 66 & 32 & 862 \\
\hline \multicolumn{10}{|l|}{ Diseases } \\
\hline Diabetes & $0.7 \%$ & $33.5 \%$ & $42.0 \%$ & $12.5 \%$ & $39.0 \%$ & $17.6 \%$ & $22.7 \%$ & $84.4 \%$ & $25.9 \%$ \\
\hline Rheumatoid arthritis & $0.0 \%$ & $7.5 \%$ & $2.0 \%$ & $9.4 \%$ & $0.0 \%$ & $4.0 \%$ & $0.0 \%$ & $12.5 \%$ & $4.2 \%$ \\
\hline $\begin{array}{l}\text { Coronary artery } \\
\text { disease }\end{array}$ & $0.0 \%$ & $5.3 \%$ & $88.0 \%$ & $17.2 \%$ & $3.4 \%$ & $9.1 \%$ & $22.7 \%$ & $59.4 \%$ & $18.9 \%$ \\
\hline $\begin{array}{l}\text { Elevated blood } \\
\text { pressure }\end{array}$ & $1.4 \%$ & $69.6 \%$ & $58.0 \%$ & $57.8 \%$ & $49.2 \%$ & $48.3 \%$ & $43.9 \%$ & $87.5 \%$ & $49.4 \%$ \\
\hline $\begin{array}{l}\text { Blood circulation } \\
\text { problems in the brain }\end{array}$ & $0.0 \%$ & $8.8 \%$ & $6.0 \%$ & $6.3 \%$ & $0.0 \%$ & $7.4 \%$ & $1.5 \%$ & $43.8 \%$ & $6.7 \%$ \\
\hline $\begin{array}{l}\text { Blood circulation } \\
\text { problems in the legs }\end{array}$ & $0.0 \%$ & $3.5 \%$ & $5.0 \%$ & $15.6 \%$ & $10.2 \%$ & $11.4 \%$ & $100.0 \%$ & $78.1 \%$ & $16.2 \%$ \\
\hline hypothyroidism & $0.0 \%$ & $4.0 \%$ & $15.0 \%$ & $14.1 \%$ & $98.3 \%$ & $5.7 \%$ & $7.6 \%$ & $28.1 \%$ & $13.3 \%$ \\
\hline Cancer & $0.0 \%$ & $18.1 \%$ & $2.0 \%$ & $1.6 \%$ & $5.1 \%$ & $5.7 \%$ & $7.6 \%$ & $31.3 \%$ & $8.4 \%$ \\
\hline Asthma & $0.0 \%$ & $1.8 \%$ & $6.0 \%$ & $95.3 \%$ & $6.8 \%$ & $9.1 \%$ & $4.5 \%$ & $40.6 \%$ & $12.4 \%$ \\
\hline COPD & $0.0 \%$ & $1.3 \%$ & $1.0 \%$ & $17.2 \%$ & $1.7 \%$ & $2.8 \%$ & $1.5 \%$ & $31.3 \%$ & $3.7 \%$ \\
\hline Heart failure & $0.0 \%$ & $4.8 \%$ & $37.0 \%$ & $4.7 \%$ & $5.1 \%$ & $2.8 \%$ & $6.1 \%$ & $71.9 \%$ & $10.0 \%$ \\
\hline Osteoporosis & $0.0 \%$ & $0.9 \%$ & $0.0 \%$ & $1.6 \%$ & $8.5 \%$ & $27.8 \%$ & $3.0 \%$ & $18.8 \%$ & $7.5 \%$ \\
\hline $\begin{array}{l}\text { Moderate or severe } \\
\text { cognitive impairment }\end{array}$ & $2.9 \%$ & $0.9 \%$ & $2.0 \%$ & $1.6 \%$ & $1.7 \%$ & $5.7 \%$ & $0.0 \%$ & $12.5 \%$ & $2.8 \%$ \\
\hline $\begin{array}{l}\text { Mild cognitive } \\
\text { impairment }\end{array}$ & $0.0 \%$ & $21.6 \%$ & $11.0 \%$ & $9.4 \%$ & $8.5 \%$ & $8.5 \%$ & $9.1 \%$ & $53.1 \%$ & $12.6 \%$ \\
\hline Depression & $0.0 \%$ & $2.6 \%$ & $6.0 \%$ & $9.4 \%$ & $5.1 \%$ & $8.0 \%$ & $0.0 \%$ & $21.9 \%$ & $4.9 \%$ \\
\hline
\end{tabular}

Values are percentages among the cluster. Highlighted values represent conditions with higher prevalence in the cluster than in the total sample. COPD chronic obstructive pulmonary disease

chronic). None of the clusters was associated with higher risk of one-time falling. In the validation sample, cluster 8 (multiple chronic disease), was also significantly associated with recurrent falling $(p=0.006)$ and none of the clusters formed with the validation sample were associated with one-time falling.

\section{Discussion}

This study examined the association between chronic diseases and falls in a sample of older people (age 6598) and demonstrated that fall incidence among community-dwelling older people is highly linked to presence of chronic disease. Individuals with five, six or more chronic diseases had significantly higher fall rates compared to those without diseases and several individual chronic diseases were associated with increased fall rates. The study showed, by clustering chronic diseases, that combinations of chronic diseases play a role in falls. The group with multiple chronic conditions had significantly higher risk of recurrent falling relative to the group of low chronic disease subjects. Osteoporosis did not cluster clearly with other diseases, but the group with osteoporosis was associated with increased risk of recurrent falls when compared with the group with low chronic disease.

The prevalence of recurrent fallers increased with age, which aligns with previous findings in the literature [3, $4,6,8,48]$. We also found that the percentage of subjects who reported poor sleep quality is higher in the recurrent fallers group and one-time fallers group compared to non-fallers $(19.5,12.5,7.1 \%$, respectively), and similar findings were made regarding frailty according to the modified SOF-index (40, 7.6 and 5.7\%), and malnutrition according to MNA (37.5, 22.5 and 12.3\%). The prevalence of recurrent fallers is higher among older adults with self-reported urinary incontinence and dizziness, which supports the findings in other studies [30, 49]. The number of falls differed between subjects with diabetes, rheumatoid arthritis, blood circulation problems in the brain and legs, cardiac failure, Parkinson's disease, osteoporosis, moderate or severe cognitive impairment, mild cognitive impairment, depression, 
Table 5 Study group characteristics by cluster

\begin{tabular}{|c|c|c|c|c|c|c|c|c|c|}
\hline Cluster & 1 & 2 & 3 & 4 & 5 & 6 & 7 & 8 & Total \\
\hline Label & $\begin{array}{l}\text { Low } \\
\text { chronic } \\
\text { disease }\end{array}$ & $\begin{array}{l}\text { Elevated } \\
\text { blood } \\
\text { pressure }\end{array}$ & $\begin{array}{l}\text { Coronary } \\
\text { artery disease }\end{array}$ & Asthma & Hypothyroidism & Osteoporosis & $\begin{array}{l}\text { Blood circulation } \\
\text { problems in legs }\end{array}$ & $\begin{array}{l}\text { Multiple } \\
\text { chronic } \\
\text { disease }\end{array}$ & \\
\hline \multicolumn{10}{|l|}{ Age } \\
\hline $65-74$ & $81.9 \%$ & $60.8 \%$ & $45.0 \%$ & $78.1 \%$ & $67.8 \%$ & $59.7 \%$ & $60.6 \%$ & $21.9 \%$ & $62.4 \%$ \\
\hline $75-84$ & $15.2 \%$ & $33.9 \%$ & $44.0 \%$ & $17.2 \%$ & $27.1 \%$ & $30.7 \%$ & $33.3 \%$ & $53.1 \%$ & $30.4 \%$ \\
\hline$\geq 85$ & $2.9 \%$ & $5.3 \%$ & $11.0 \%$ & $4.7 \%$ & $5.1 \%$ & $9.7 \%$ & $6.1 \%$ & $25.0 \%$ & $7.2 \%$ \\
\hline \multicolumn{10}{|l|}{$B M I$} \\
\hline$<20$ & $2.9 \%$ & $0.9 \%$ & $3.1 \%$ & $1.6 \%$ & $1.8 \%$ & $4.6 \%$ & $1.6 \%$ & $0.0 \%$ & $2.4 \%$ \\
\hline $20-24,9$ & $38.0 \%$ & $30.1 \%$ & $29.6 \%$ & $44.4 \%$ & $26.3 \%$ & $38.2 \%$ & $38.1 \%$ & $28.1 \%$ & $34.3 \%$ \\
\hline $25-29,9$ & $50.4 \%$ & $48.4 \%$ & $50.0 \%$ & $31.7 \%$ & $54.4 \%$ & $35.3 \%$ & $39.7 \%$ & $31.3 \%$ & $44.1 \%$ \\
\hline$>30$ & $8.8 \%$ & $20.5 \%$ & $17.3 \%$ & $22.2 \%$ & $17.5 \%$ & $22.0 \%$ & $20.6 \%$ & $40.6 \%$ & $19.2 \%$ \\
\hline \multicolumn{10}{|l|}{ Daily activity } \\
\hline$<1 \mathrm{~h}$ & $13.1 \%$ & $15.7 \%$ & $20.6 \%$ & $20.6 \%$ & $17.2 \%$ & $18.6 \%$ & $6.3 \%$ & $32.3 \%$ & $16.8 \%$ \\
\hline $1-2 \mathrm{~h}$ & $25.5 \%$ & $38.6 \%$ & $29.9 \%$ & $31.7 \%$ & $43.1 \%$ & $33.1 \%$ & $35.9 \%$ & $32.3 \%$ & $33.7 \%$ \\
\hline$>2 \mathrm{~h}$ & $61.3 \%$ & $45.7 \%$ & $49.5 \%$ & $47.6 \%$ & $39.7 \%$ & $48.3 \%$ & $57.8 \%$ & $35.5 \%$ & $49.5 \%$ \\
\hline $\begin{array}{l}\text { Urinary } \\
\text { incontinence }\end{array}$ & $0.7 \%$ & $8.4 \%$ & $25.0 \%$ & $15.6 \%$ & $33.9 \%$ & $61.9 \%$ & $10.6 \%$ & $75.0 \%$ & $24.9 \%$ \\
\hline Dizziness & $0.0 \%$ & $15.0 \%$ & $26.0 \%$ & $17.2 \%$ & $8.5 \%$ & $62.5 \%$ & $30.3 \%$ & $71.9 \%$ & $26.6 \%$ \\
\hline \multicolumn{10}{|l|}{ SOF-index } \\
\hline Robust & $84.2 \%$ & $65.4 \%$ & $60.4 \%$ & $75.0 \%$ & $72.7 \%$ & $62.2 \%$ & $72.7 \%$ & $33.3 \%$ & $67.9 \%$ \\
\hline Intermediate & $13.5 \%$ & $25.1 \%$ & $30.8 \%$ & $21.9 \%$ & $20.0 \%$ & $28.7 \%$ & $21.2 \%$ & $30.0 \%$ & $23.8 \%$ \\
\hline Frail & $2.3 \%$ & $9.5 \%$ & $8.8 \%$ & $3.1 \%$ & $7.3 \%$ & $9.1 \%$ & $6.1 \%$ & $36.7 \%$ & $8.2 \%$ \\
\hline \multicolumn{10}{|l|}{ MNA Index } \\
\hline Malnutrition & $0.9 \%$ & $1.6 \%$ & $0.0 \%$ & $2.4 \%$ & $0.0 \%$ & $1.0 \%$ & $2.4 \%$ & $0.0 \%$ & $1.1 \%$ \\
\hline Risk of maln. & $7.0 \%$ & $12.5 \%$ & $6.1 \%$ & $19.0 \%$ & $9.4 \%$ & $23.0 \%$ & $14.3 \%$ & $42.1 \%$ & $14.3 \%$ \\
\hline Normal nutr. & $92.1 \%$ & $85.9 \%$ & $93.9 \%$ & $78.6 \%$ & $90.6 \%$ & $76.0 \%$ & $83.3 \%$ & $57.9 \%$ & $84.6 \%$ \\
\hline
\end{tabular}

Percentages among the clusters. BMI Body Mass Index, SOF SOF Frailty Index (Study of Osteoporotic Fractures), MNA Mini Nutritional Assessment. Highlighted values represent conditions with higher prevalence in the cluster than in the total sample

dizziness, and urinary incontinence compared to subjects without the specific condition. These diseases and geriatric conditions have been found to increase fall risk also in previous studies [1, 7, 17-26].

Our results showed a correlation between multiple chronic diseases and recurrent falls. Compared to the no disease group with age adjustment, increase in the risk of recurrent falls was found in the group having five or more diseases. This finding is supported by the findings in previous studies $[32,50]$. We also found by clustering diseases that the multiple chronic disease group had a significantly higher risk of having fallen recurrently during the last 3 months than the group of low chronic diseases. Subjects in the osteoporotic cluster also had a high prevalence of elevated blood pressure and were more likely to have fallen during the last 3 months. It is also important to note that not all clusters were associated with high fall risk and none of the disease clusters was significantly associated with higher risk of one-time falling. This finding supports the previous findings of different characteristics of one-time fallers and recurrent fallers [14-16]. All clusters, except the low chronic cluster, had a notable percentage of subjects with elevated blood pressure (43.9-87.5\%). The highest prevalence was in the multiple chronic disease cluster and elevated blood pressure was, in fact, the most common disease within that cluster. Our results partly align with previous studies. Sibley et al. found in their Canadian populationbased study that clusters of hypertension and COPD had higher risk of falling than the low chronic diseases cluster [32]. In an earlier study by Paliwal et al., a positive association was found between the number of falls and certain diseases; heart attack, angina, stroke, asthma, COPD, chronic kidney disease, arthritis, depression, and diabetes [35]. The combinations of diseases associated with higher prevalence of falling differ between our 
Table 6 Association between cluster of chronic conditions and one-time falls and recurrent falls according to multinomial logistic regression analyses adjusted for age and sex. Results presented as odds ratios (OR) and 95\% confidence intervals (95\% Cl)

\begin{tabular}{|c|c|c|c|}
\hline & Variable & OR $(95 \% \mathrm{Cl})$ & $p$-value \\
\hline \multirow[t]{12}{*}{1 fall } & 1 Low-chronic & reference & \\
\hline & 2 Elevated blood pressure & $0.87(0.35-2.16)$ & 0.766 \\
\hline & 3 Coronary heart disease & $1.41(0.53-3.76)$ & 0.492 \\
\hline & 4 Asthma & $0.73(0.18-2.91)$ & 0.650 \\
\hline & 5 Hypothyroidism & $1.87(0.62-5.66)$ & 0.268 \\
\hline & 6 Osteoporosis & $1.36(0.55-3.37)$ & 0.512 \\
\hline & 7 Blood circulation problems in the legs & $0.75(0.21-2.69)$ & 0.662 \\
\hline & 8 Multi-chronic & $0.60(0.11-3.11)$ & 0.539 \\
\hline & Age 65-74 & reference & \\
\hline & Age $75-84$ & $4.96(2.81-8.74)$ & $<0.001$ \\
\hline & Age $\geq 85$ & $3.12(1.18-8.29)$ & 0.022 \\
\hline & Gender (male) & $1.05(0.62-1.78)$ & 0.871 \\
\hline \multirow[t]{12}{*}{2 or more falls } & 1 Low-chronic & reference & \\
\hline & 2 Elevated blood pressure & $1.80(0.35-9.13)$ & 0.480 \\
\hline & 3 Coronary heart disease & $4.93(0.98-24.90)$ & 0.054 \\
\hline & 4 Asthma & $1.03(0.09-11.60)$ & 0.984 \\
\hline & 5 Hypothyroidism & $2.60(0.35-19.22)$ & 0.350 \\
\hline & 6 Osteoporosis & $5.65(1.23-25.85)$ & 0.026 \\
\hline & 7 Blood circulation problems in the legs & $3.12(0.50-19.37)$ & 0.223 \\
\hline & 8 Multi-chronic & $13.42(2.47-72.96)$ & 0.003 \\
\hline & Age 65-74 & reference & \\
\hline & Age $75-84$ & $1.186(0.559-2.515)$ & 0.657 \\
\hline & Age $\geq 85$ & $3.076(1.245-7.600)$ & 0.015 \\
\hline & Gender (male) & $1.072(0.547-2.101)$ & 0.839 \\
\hline
\end{tabular}

In the multinomial regression, the reference group is non-fallers and the 2 comparison groups are persons with 1 fall and persons with 2 or more falls. Lowchronic group, age group 65-74 and female gender are used as reference groups

study and the studies by Sibley et al. and Paliwal et al. This may be due to slightly different questionnaires used to collect information on medical history and diagnoses and different lists of asked diseases. In addition, we had a relatively low sample size compared to previous two studies and we had to exclude some of the diseases from clustering due to low prevalence of these diseases in the total sample. Similarly as in the previous studies, we did not collect any information on the treatment of the diseases, which may have had an impact on the results. National differences may also exist. In another study, Ek et al. used sociodemographic and lifestyle-related characteristics in forming clusters and had a follow-up period of 5 years. Their finding was that participants with unhealthy lifestyle and a high burden of chronic disease had higher risk of falling over a longer period of followup (5 and 10 years) compared to those in the reference group [34].

The strength of this study is its population-based sample and analysis as well as its rather unique approach of clustering diseases and studying their association with falls. However, some limitations of this study need to be taken into account. Firstly, the questionnaire was completed only once and no follow-up period was included. Furthermore, we have no information if the diagnosis of the certain chronic disease was given before or after the occurrence of falls, and no specific information about the diseases, such as the type or location of cancers. We also did not study how severe the diseases were or how the diseases or conditions were controlled or medicated. Cognitive impairments may also affect the results. The prevalence of certain diagnosis of some pathologies such as dementia or osteoporosis may be underestimated. Some diseases have low prevalence and, for example, Parkinson's disease was not included in the cluster analysis even though it is commonly known to produce a high risk of falls. The three-month recall time may also lead to absence of actual recurrent falls in our study sample and the actual amount of recurrent fallers may be higher [51]. A larger population sample, for example 
from health records, would give more information about the chronic diseases and falls and show the potential of using health records in automatic screening of persons with high fall risk.

Our study gives promising results about the association between diseases and falls and further implicates that using data sources such as patient health records for screening for high fall risk individuals is important. In addition, the use of machine learning methods in health records for screening for high-risk persons is still unexploited. Future studies should utilize available data sources from patient records to study the association between combination of diagnoses and falls. Studies with large data sets should consider utilizing machine learning when analyzing the relationship between clusters of chronic conditions and falls.

\section{Conclusions}

This study supports the earlier findings that risk of recurrent falls increases with age. The results further indicate that persons with certain combinations of chronic diseases may have elevated fall risk and the risk is highest with multiple chronic conditions. Multiple chronic disease cluster participants were, in general, older, less physically active, overweight, at risk of malnutrition, and had more geriatric conditions compared to the low chronic cluster. In addition to the multiple chronic disease cluster, clusters where osteoporosis and elevated blood pressure were the defining factors had significantly higher risk of falls. Notably, persons with five or more chronic conditions reported significantly more often having fallen at least two times within the last 3 months. Although further studies with a larger population are needed, these results implicate the potential of identifying high-risk persons by analyzing health record data. Finally, the results show that certain combinations of chronic diseases, especially multiple chronic conditions, increase the risk of recurrent falls.

\section{Supplementary information}

Supplementary information accompanies this paper at https://doi.org/10. 1186/s12877-020-01621-9.

Additional file 1. GASEL questionnaire (English version). Translated version of the study questionnaire. Original language of the questionnaire is Finnish. Linguistic validation between Finnish and English versions has not been performed.

\section{Abbreviations}

BMI: Body Mass Index; Cl: Confidence Interval; COPD: Chronic Obstructive Pulmonary Disease; IQR: Interquartile range; MNA: Mini Nutritional Assessment; OR: Odds ratio; SOF: Study of Osteoporotic Fractures

\section{Acknowledgements}

Parts of the manuscript of this article were included in Doctor of Philosophy thesis of the first author: Immonen, M. (2020). Risk factors for falls and technologies for fall risk assessment in older adults. University of Oulu, Finland (http://jultika.oulu.fi/files/isbn9789526225067.pdf). The thesis was a summary of five publications, of which the present article is one.

\section{Authors' contributions}

$\mathrm{MI}$ was the main responsible for conducting the statistical analyses and preparing the manuscript, and participated in designing the study and collecting the data. HS participated in designing the study, data collection and writing the manuscript. MH participated in the statistical analyses and writing the manuscript. HE participated in designing of the study and in writing the manuscript. NK and MK both participated in designing and management of the study, data collection and manuscript writing. TJ participated in designing of the study and writing the manuscript. RK was responsible for the scientific quality of the study, led the study design and data collection, and participated in writing the manuscript. All authors read and approved the final manuscript.

\section{Funding}

The GASEL project was supported by Business Finland (during the project known as Tekes, the Finnish Funding Agency for Innovation) and University of Oulu. Additionally, VTT Technical Research Centre of Finland Ltd. supported writing the manuscript.

\section{Availability of data and materials}

Data cannot be shared publicly because it includes sensitive personal health related data. Data are available from the University of Oulu Institutional Data Access (NFBC Project center: projectcenter@oulu.fi) for researchers who meet the criteria for access to confidential data. The possibilities for data sharing (anonymized or using pseudonyms) with researchers outside project consortium will be evaluated case by case by the NFBC Scientific Committee.

\section{Ethics approval and consent to participate}

The study protocol was approved by the Ethics Committee of Human Sciences at the University of Oulu (statement 6/2014). The participants were informed about the study and they gave their written informed consent.

\section{Consent for publication}

Not applicable.

\section{Competing interests}

The authors declare that they have no competing interests.

\section{Author details}

${ }^{1}$ VTT Technical Research Centre of Finland Ltd. Kaitoväylä 1, P.O.Box 1100, Fl-90571 Oulu, Finland. ${ }^{2}$ Center for Life Course Health Research, University of Oulu, P.O. Box 5000, Fl-90014 Oulu, Finland. ${ }^{3}$ Department of Diagnostic Radiology, Oulu University Hospital, Kajaanintie 50, Fl-90220 Oulu, Finland. ${ }^{4}$ Medical Research Centre Oulu (MRC), Oulu University Hospital and University of Oulu, P.O. Box 5000, Fl-90014 Oulu, Finland. ${ }^{5}$ Information Studies, University of Oulu, P.O.Box 8000, FI-90014 Oulu, Finland. ${ }^{6}$ Research Unit of Medical Imaging, Physics and Technology, University of Oulu, P.O. Box 5000, Fl-90014 Oulu, Finland. ${ }^{7}$ Department of Sports and Exercise Medicine, Oulu Deaconess Institute Foundation sr, Albertinkatu 16, Fl-90100 Oulu, Finland.

Received: 4 October 2019 Accepted: 18 June 2020

Published online: 26 June 2020

References

1. Tinetti ME, Speechley M, Ginter SF. Risk factors for falls among elderly persons living in the community. N Engl J Med. 1988;319:1701-7. https:// doi.org/10.1056/NEJM198812293192604

2. Blake AJ, Morgan K, Bendall MJ, Dallosso H, Ebrahim SBJ, Arie THD, et al. Falls by elderly people at home: prevalence and associated factors. Age Ageing. 1988;17:365-72. https://doi.org/10.1093/ageing/17.6.365.

3. Downton JH. Falls in the elderly: CRC Press, Hodder Arnold Publication; 1993. ISBN 0340548487.

4. Lord Sherrington C, Menz HB. F a L L S in older people risk factors and strategies for prevention: Cambridge Univ. Press; 2001.

5. Hill K, Schwarz J, Flicker L, Carroll S. Falls among healthy, communitydwelling, older women: a prospective study of frequency, circumstances, 
consequences and prediction accuracy. Aust N Z J Public Health. 1999;23: 41-8. https://doi.org/10.1111/j.1467-842x.1999.tb01203.x.

6. WHO Global Report on Falls Prevention in Older Age. Community Health (Bristol). 2007, 53.

7. Gale CR, Cooper C, Aihie Sayer A. Prevalence and risk factors for falls in older men and women: the English longitudinal study of ageing. Age Ageing. 2016;45:789-94. https://doi.org/10.1093/ageing/afw129.

8. Rubenstein LZ, Josephson KR. Falls and their prevention in elderly people: what does the evidence show? Med Clin North Am. 2006;90:807-24. https:// doi.org/10.1016/.mcna.2006.05.013.

9. Patil R, Uusi-Rasi K, Kannus P, Karinkanta S, Sievänen H. Concern about falling in older women with a history of falls: associations with health, functional ability, physical activity and quality of life. Gerontology. 2014;60: 22-30. https://doi.org/10.1159/000354335.

10. Li F, Fisher KJ, Harmer P, McAuley E, Wilson NL. Fear of falling in elderly persons: association with falls, functional ability, and quality of life. J Gerontol Ser B Psychol Sci Soc Sci. 2003;58:283-P290. https://doi.org/10. 1093/geronb/58.5.P283.

11. Delbaere K, Crombez G, Vanderstraeten G, Willems T, Cambier D. Fearrelated avoidance of activities, falls and physical frailty. A prospective community-based cohort study. Br Geriatr Soc. 2004;33:368-73. https://doi. org/10.1093/ageing/afh106.

12. WHO Global health and ageing. 2011, 11-7737.

13. Pluijm SMF, Smit JH, Tromp EAM, Stel VS, Deeg DJH, Bouter LM, et al. A risk profile for identifying community-dwelling elderly with a high risk of recurrent falling: results of a 3-year prospective study. Osteoporos Int. 2006; 17:417-25. https://doi.org/10.1007/s00198-005-0002-0.

14. Anstey KJ, Wood J, Kerr G, Caldwell H, Lord SR. Different cognitive profiles for single compared with recurrent fallers without dementia. Neuropsychology. 2009;23:500-8. https://doi.org/10.1037/a0015389.

15. Lord SR, Ward JA, Williams P, Anstey KJ. Physiological factors associated with falls in older community-dwelling women. J Am Geriatr Soc. 1994;42: 1110-7. https://doi.org/10.1111/j.1532-5415.1994.tb06218.x.

16. Kelsey JL, Procter-Gray E, Berry SD, Hannan MT, Kiel DP, Lipsitz LA, et al. Reevaluating the implications of recurrent falls in older adults: location changes the inference. J Am Geriatr Soc. 2012;60:517-24. https://doi.org/10. 1111/j.1532-5415.2011.03834.x.

17. Pickering RM, Grimbergen YAM, Rigney U, Ashburn A, Mazibrada G, Wood B, et al. A meta-analysis of six prospective studies of falling in Parkinson's disease. Mov Disord. 2007;22:1892-900. https://doi.org/10.1002/mds.21598.

18. Stolze H, Klebe S, Zechlin C, Baecker C, Friege L, Deuschl G. Falls in frequent neurological diseases. J Neurol. 2004;251:79-84. https://doi.org/10.1007/ s00415-004-0276-8.

19. Lee K, Pressler SJ, Titler M. Falls in patients with heart failure. J Cardiovasc Nurs. 2016;31:555-61. https://doi.org/10.1097/JCN.0000000000000292.

20. Allali G, Launay CP, Blumen HM, Callisaya ML, De Cock A-M, Kressig RW, et al. Falls, cognitive impairment, and gait performance: results from the GOOD initiative. J Am Med Dir Assoc. 2017;18:335-40. https://doi.org/10. 1016/.j.jamda.2016.10.008.

21. Yang $Y$, Hu X, Zhang Q, Zou R. Diabetes mellitus and risk of falls in older adults: a systematic review and meta-analysis. Age Ageing. 2016;45:761-7. https://doi.org/10.1093/ageing/afw140.

22. Brenton-Rule A, Dalbeth N, Bassett S, Menz HB, Rome K. The incidence and risk factors for falls in adults with rheumatoid arthritis: a systematic review. Semin Arthritis Rheum. 2015;44:389-98. https://doi.org/10.1016/J. SEMARTHRIT.2014.08.001

23. Deandrea S, Lucenteforte E, Bravi F, Foschi R, La Vecchia C, Negri E. Risk factors for falls in community-dwelling older people: a systematic review and meta-analysis. Epidemiology. 2010;21:658-68. https://doi.org/10.1097/ EDE.0b013e3181e89905.

24. Kistler BM, Khubchandani J, Wiblishauser M, Wilund KR, Sosnoff JJ. Epidemiology of falls and fall-related injuries among middle-aged adults with kidney disease. Int Urol Nephrol. 2019:1-9. https://doi.org/10.1007/s11255-019-02148-8.

25. Kistler BM, Khubchandani J, Jakubowicz G, Wilund K, Sosnoff J. Falls and fallrelated injuries among US adults aged 65 or older with chronic kidney disease. Prev Chronic Dis. 2018;15:E82. https://doi.org/10.5888/pcd15.170518.

26. Kanis JA. Diagnosis of osteoporosis and assessment of fracture risk. Lancet. 2002;359:1929-36. https://doi.org/10.1016/S0140-6736(02)08761-5.

27. Wolff JL, Starfield B, Anderson G. Prevalence, expenditures, and complications of multiple chronic conditions in the elderly. Arch Intern Med. 2002;162:2269. https://doi.org/10.1001/archinte.162.20.2269.
28. Excoffier S, Herzig L, N'Goran AA, Déruaz-Luyet A, Haller DM. Prevalence of multimorbidity in general practice: a cross-sectional study within the Swiss sentinel surveillance system (Sentinella). BMJ Open. 2018;8:e019616. https:// doi.org/10.1136/bmjopen-2017-019616.

29. Sakib MN, Shooshtari S, St John P, Menec V. The prevalence of multimorbidity and associations with lifestyle factors among middle-aged Canadians: an analysis of Canadian longitudinal study on aging data. BMC Public Health. 2019;19:243. https://doi.org/10.1186/s12889-019-6567-x.

30. Lee PG, Cigolle C, Blaum C. The co-occurrence of chronic diseases and geriatric syndromes: the health and retirement study. J Am Geriatr Soc. 2009;57:511-6. https://doi.org/10.1111/j.1532-5415.2008.02150.x.

31. Davis JW, Chung R, Juarez DT. Prevalence of comorbid conditions with aging among patients with diabetes and cardiovascular disease. Hawaii Med J. 2011;70:209-13.

32. Sibley KM, Voth J, Munce SE, Straus SE, Jaglal SB. Chronic disease and falls in community-dwelling Canadians over 65 years old: a population-based study exploring associations with number and pattern of chronic conditions. BMC Geriatr. 2014;14:22. https://doi.org/10.1186/1471-2318-14-22.

33. Teixeira L, Araújo L, Duarte N, Ribeiro O. Falls and fear of falling in a sample of centenarians: the role of multimorbidity, pain and anxiety. Psychogeriatrics. 2019. https://doi.org/10.1111/psyg.12423.

34. Ek S, Rizzuto D, Fratiglioni L, Johnell K, Xu W, Welmer A-K. Risk profiles for injurious falls in people over 60: a population-based cohort study. J Gerontol Ser A. 2018;73:233-9. https://doi.org/10.1093/gerona/glx115.

35. Paliwal Y, Slattum PW, Ratliff SM. Chronic health conditions as a risk factor for falls among the community-dwelling US older adults: a zero-inflated regression modeling approach. Biomed Res Int. 2017;2017:5146378. https:// doi.org/10.1155/2017/5146378.

36. Diederichs C, Berger K, Bartels DB. The measurement of multiple chronic diseases - a systematic review on existing multimorbidity indices. I Gerontol Ser A. 2010;66A:301-11. https://doi.org/10.1093/gerona/glq208.

37. Fortin M, Stewart M, Poitras ME, Almirall J, Maddocks H. A systematic review of prevalence studies on multimorbidity: toward a more uniform methodology. Ann Fam Med. 2012;10:142-51.

38. Griffith LE, Gruneir A, Fisher KA, Nicholson K, Panjwani D, Patterson C, et al. Key factors to consider when measuring multimorbidity. J Comorbidity. 2018:8:2235042X1879530. https://doi.org/10.1177/2235042×18795306.

39. Kuntien avainluvut muuttujina. PxWeb Available online: https://pxnet2.stat.fi/ PXWeb/pxweb/fi/Kuntien_avainluvut/Kuntien_avainluvut_2019/kuntien_ avainluvut_2019_aikasarja.px/table/tableViewLayout1/?rxid=444223df-f91 c-4479-891f-5dcd50b983d2 (Accessed on Sep 13, 2019).

40. Ganz DA, Higashi T, Rubenstein LZ. Monitoring falls in cohort studies of community-dwelling older people: effect of the recall interval. J Am Geriatr Soc. 2005:53:2190-4.

41. Yoo J, Kim S, Park W-C, Kim B-S, Choi H, Won CW. Discrepancy between quarterly recall and annual recall of falls: a survey of older adults. Ann Geriatr Med Res. 2017;21:174-81. https://doi.org/10.4235/agmr.2017.21.4.174.

42. Järvenpää T, Rinne JO, Koskenvuo M, Räihä I, Kaprio J. Binge drinking in midlife and dementia risk. Epidemiology. 2005;16:766-71. https://doi.org/10 1097/01.ede.0000181307.30826.6c.

43. Pyky R, Jauho A-M, Ahola R, Ikäheimo TM, Koivumaa-Honkanen H, Mäntysaari $\mathrm{M}$, et al. Profiles of sedentary and non-sedentary young men - a population-based MOPO study. BMC Public Health. 2015;15:1164. https://doi. org/10.1186/s12889-015-2495-6.

44. Ensrud KE, Ewing SK, Cawthon PM, Fink HA, Taylor BC, Cauley JA, et al. A comparison of frailty indexes for the prediction of falls, disability, fractures and mortality in older men. J Am Geriatr Soc. 2009;57:492-8. https://doi.org/ 10.1111/j.1532-5415.2009.02137.x.

45. Keränen $N S$, Kangas $M$, Immonen $M$, Similä $H$, Enwald $H$, Korpelainen $R$, et al. Use of information and communication technologies among older people with and without frailty: a population-based survey. J Med Internet Res. 2017;19:e29. https://doi.org/10.2196/jmir.5507.

46. Guigoz Y, Vellas B, Garry PJ. Assessing the nutritional status of the elderly: the mini nutritional assessment as part of the geriatric evaluation. Nutr Rev. 1996;54:S59-65.

47. Cornell JE, Pugh JA, Williams JW Jr, Kazis L, Lee AFS, Parchman ML, et al. Multimorbidity clusters: clustering binary data from multimorbidity clusters: clustering binary data from a large administrative medical database. Appl Multivar Res. 2009;12:163. https://doi.org/10.22329/amr.v12i3.658.

48. Masud T, Morris RO. Epidemiology of falls. Age Ageing. 2001;30:3-7. https:// doi.org/10.1093/ageing/30.suppl_4.3. 
49. Brown JS, Vittinghoff E, Wyman JF, Stone KL, Nevitt MC, Ensrud KE, et al. Urinary incontinence: does it increase risk for falls and fractures? J Am Geriatr Soc. 2000;48:721-5. https://doi.org/10.1111/j.1532-5415.2000. tb04744.x.

50. Lawlor DA, Patel R, Ebrahim S. Association between falls in elderly women and chronic diseases and drug use: cross sectional study. BMJ. 2003;327: 712-7. https://doi.org/10.1136/bmj.327.7417.712.

51. Fleming J, Matthews FE, Brayne C. Falls in advanced old age: recalled falls and prospective follow-up of over-90-year-olds in the Cambridge City over-75s cohort study. BMC Geriatr. 2008;8:6. https://doi.org/10. 1186/1471-2318-8-6.

\section{Publisher's Note}

Springer Nature remains neutral with regard to jurisdictional claims in published maps and institutional affiliations.

Ready to submit your research? Choose BMC and benefit from:

- fast, convenient online submission

- thorough peer review by experienced researchers in your field

- rapid publication on acceptance

- support for research data, including large and complex data types

- gold Open Access which fosters wider collaboration and increased citations

- maximum visibility for your research: over $100 \mathrm{M}$ website views per year

At $\mathrm{BMC}$, research is always in progress.

Learn more biomedcentral.com/submissions 